\title{
The application of metagenomic next- generation sequencing in diagnosing Chlamydia psittaci pneumonia: a report of five cases
}

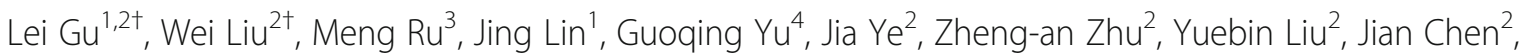
Guoxiang $\mathrm{Lai}^{2}$ and Wen Wen ${ }^{2 *}$

\begin{abstract}
Background: Chlamydia psittaci pneumonia is a zoonotic infectious disease caused by Chlamydia psittaci. Diagnostic tools, including culture, serologic test and PCR-based methods, are available but prone to false negative results.

Case presentation: This report included five cases of Chlamydia psittaci pneumonia. Symptoms and signs common to all 5 cases included fever, coughing, generalized muscle ache, and most notably, inflammatory infiltration of the lungs upon chest $C T$ and $X$-ray. Metagenomic next-generation sequencing (mNGS) revealed the presence of Chlamydia psittaci in biopsy lung tissue in 3 cases and bronchoalveolar lavage fluid in the remaining 2 cases. Three patients responded to doxycycline plus moxifloxacin; two patients responded to moxifloxacin alone.
\end{abstract}

Conclusions: mNGS could be used to diagnose Chlamydia psittaci pneumonia.

Keywords: mNGS, Chlamydia psittaci, Case report

\section{Background}

Chlamydia psittaci is an obligatory intra-cellular Gramnegative bacterium that typically infects birds, but could occasionally cause psittacosis in humans when contaminated aerosols from infected birds are inhaled. Chlamydia psittaci pneumonia in humans is underestimated due to low awareness of the disease and atypical clinical presentation in majority of the cases [1-3]. The low sensitivity and complex procedure of Chlamydia psittaci culture causes it hardly routinely performed in most diagnostic laboratories. Other laboratory testing included

\footnotetext{
* Correspondence: fjfzfisher@163.com

${ }^{+}$Lei Gu and Wei Liu contributed equally to this work.

${ }^{2}$ Department of Respiratory and Critical Care Medicine, Dongfang Hospital of Xiamen University, Fuzhou General Hospital of Fujian Medical University, The 900th Hospital of the Joint Logistic Support Force, PLA, Gulou, Fuzhou 350025, China

Full list of author information is available at the end of the article
}

serological assay and polymerase chain reaction (PCR) based methods, but both have questionable sensitivity and specificity [2]. Untargeted metagenomic nextgeneration sequencing (mNGS) has been increasingly used in the diagnosis of infectious diseases, particularly when conventional diagnostic approaches have limitations [4]. Here we report 5 cases of Chlamydia psittaci pneumonia, in which the diagnosis was established with mNGS. All together, mNGS was conducted in a total of 120 pneumonia cases in the index period. Demographical and basic clinical features of the 5 cases are summarized in Table 1.

\section{Case presentation \\ Case \#1}

An 81-year-old woman was transferred to us with fever, productive coughing with white sticky sputum, and 
Table 1 Demographical and basic clinical features of the 5 patients

\begin{tabular}{|c|c|c|c|c|c|c|c|c|c|}
\hline \multirow[t]{2}{*}{ Case \# } & \multirow[t]{2}{*}{ Sex } & \multirow[t]{2}{*}{ Age (y) } & \multirow[t]{2}{*}{ Sample } & \multirow{2}{*}{$\begin{array}{l}\text { Underlying } \\
\text { diseases }\end{array}$} & \multicolumn{4}{|l|}{ Laboratory test } & \multirow{2}{*}{$\begin{array}{l}\text { metagenomics sequencing results } \\
\text { and specific reads(n) }\end{array}$} \\
\hline & & & & & routine blood test & $\begin{array}{l}\text { CRP } \\
(\mathrm{mg} / \mathrm{L})\end{array}$ & $\begin{array}{l}\mathrm{PCT} \\
(\mathrm{ng} / \mathrm{ml})\end{array}$ & $\begin{array}{l}\text { ESR } \\
(\mathrm{mm} / \mathrm{h})\end{array}$ & \\
\hline 1 & Female & 81 & BALF & $\begin{array}{l}\text { hypertension, } \\
\text { diabetes, } \\
\text { coronary artery } \\
\text { diseases }\end{array}$ & $\begin{array}{l}\text { WBC } 7.71 * 10 \wedge 9, \text { NE\% } 69.8, \\
\text { NE } 5.38 * 10 \wedge 9, \text { LN\% } 17.5 \downarrow, \\
\text { LN } 1.35 * 10^{\wedge} 9\end{array}$ & 53 & $<0.05$ & 74 & $\begin{array}{l}\text { Candida albicans (182) } \\
\text { Staphylococcus capitis (12) } \\
\text { Chlamydia psittaci (6) } \\
\text { Human betaherpesvirus } 5 \text { (2) }\end{array}$ \\
\hline 2 & Male & 45 & BALF & diabetes & $\begin{array}{l}\text { WBC } 8.22 * 10 \wedge 9, \text { NE\% } 93.1 \uparrow, \\
\text { NE } 7.65^{*} 10^{\wedge} 9 \uparrow, \text { LN\% } 4.0 \downarrow, \\
\text { LN } 0.33^{*} 10^{\wedge} 9 \downarrow\end{array}$ & 226 & 1.712 & 42 & $\begin{array}{l}\text { Chlamydia psittaci (225) } \\
\text { Lautropia mirabilis (28) } \\
\text { Leuconostoc lactis (19) } \\
\text { Rothia mucilaginosa (19) } \\
\text { Rothia dentocariosa (12) } \\
\text { Streptococcus parasanguinis (10 } \\
\text { Actinomyces odontolyticus (8) } \\
\text { Streptococcus mitis (4) }\end{array}$ \\
\hline 3 & Female & 85 & $\begin{array}{l}\text { Lung } \\
\text { tissue }\end{array}$ & none & $\begin{array}{l}\text { WBC } 6.38 * 10 \wedge 9, \text { NE\% } 88.9, \\
\text { NE } 5.67^{*} 10^{\wedge} 9, \text { LN\% } 8.0 \downarrow, \text { LN } \\
0.51 * 10^{\wedge 9}\end{array}$ & 184 & 1.64 & 64 & $\begin{array}{l}\text { Chlamydia psittaci (48) } \\
\text { Staphylococcus epidermidis (1) }\end{array}$ \\
\hline 4 & Female & 66 & $\begin{array}{l}\text { Lung } \\
\text { tissue }\end{array}$ & none & $\begin{array}{l}\text { WBC } 5.47^{*} 10 \wedge 9, \text { NE\% } 69.8, \\
\text { NE } 3.82^{*} 10^{\wedge} 9, \text { LN\% } 19.4 \downarrow \\
\text { LN } 1.06 * 10^{\wedge} 9 \downarrow\end{array}$ & 124 & 0.13 & 17 & $\begin{array}{l}\text { Chlamydia psittaci (205) } \\
\text { Corynebacterium striatum (1) } \\
\text { Klebsiella pneumoniae (1) }\end{array}$ \\
\hline 5 & Female & 61 & $\begin{array}{l}\text { Lung } \\
\text { tissue }\end{array}$ & none & $\begin{array}{l}\text { WBC } 6.88^{*} 10 \wedge 9, \text { NE\% 68.4, } \\
\text { NE } 4.70^{*} 10^{\wedge} 9, \text { LN\% } 22.7 \downarrow \\
\text { LN } 1.56^{*} 10^{\wedge} 9 \downarrow\end{array}$ & 96.7 & $<0.05$ & 37 & Chlamydia psittaci (2) \\
\hline
\end{tabular}

Abbreviations: BALF Bronchoalveolar lavage fluid, CRP C-reactive protein (normal reference range: 0-8 mg/L), ESR Erythrocyte sedimentation rate (normal < $15 \mathrm{~mm} / \mathrm{h}$ );

LN Lymphocyte, PCT Procalcitonin (normal $<0.05 \mathrm{ng} / \mathrm{ml}$ ), NE Neutrophil, WBC White blood cell

generalized muscle ache and malaise for 10 days. On the 5 th day after the onset of symptoms, she visited a local hospital. A chest computed tomography (CT) scan showed inflammatory infiltration in the lower lobe of the left lung. She was treated with moxifloxacin $(0.4 \mathrm{~g}$, I.V., qd) plus meropenem ( $1 \mathrm{~g}, \mathrm{I} . \mathrm{V} ., \mathrm{q} 12 \mathrm{~h})$ for 3 days, but fever continued (highest body temperature $39.4{ }^{\circ} \mathrm{C}$ ). A repeat CT scan suggested progression of pulmonary infection. Moxifloxacin was replaced with linezolid (600 mg, I.V., q12h), with continuing meropenem treatment. On the second day after linezolid/meropenem, fever subsided. However, other symptoms and signs continued.

Body temperature upon arriving to us was $36.7^{\circ} \mathrm{C}$. Physical examination revealed inspiratory crackles in the lower left lung. CT and chest X-ray showed alveolar consolidation in the left lower lobe (Fig. 1a, b). White blood cell was largely normal: total count $7.71 * 10^{9} / \mathrm{L}$ (reference range: $3.5-9.5^{*} 10^{9} / \mathrm{L}$ ), neutrophil count $5.38^{*} 10^{9} / \mathrm{L}\left(1.8-6.3^{*} 10^{9} / \mathrm{L}\right), 69.8 \%$ neutrophils $(40-75 \%)$, $17.5 \%$ lymphocytes $(20-50 \%)$, and lymphocytes $1.35 * 10^{9}$ / $\mathrm{L}\left(1.1-3.2^{*} 10^{9} / \mathrm{L}\right)$. C-reactive protein (CRP) was $53 \mathrm{mg} / \mathrm{L}$ $(0-8 \mathrm{mg} / \mathrm{L})$. Erythrocyte sedimentation rate (ESR) was $74 \mathrm{~mm} / \mathrm{h}(<15 \mathrm{~mm} / \mathrm{h})$. Procalcitonin (PCT) was normal $(<0.05 \mathrm{ng} / \mathrm{ml})$. Past history included hypertension, diabetes and coronary artery disease. Treatment with linezolid continued at $600 \mathrm{mg}$, I.V., q12h and meropenem was replaced with ertapenem (1 g, I.V., qd). Bronchoalveolar lavage (BAL) was conducted on the second day and
BAL fluid (BALF) was sent for testing using mNGS (KindStar Global-Wuhan). On the 6th day of arrival to our hospital, mNGS reported sequence reads of Chlamydia psittaci (Table 1). Linezolid and ertapenem were discontinued. The patient was placed on doxycycline (100 mg, P.O., q12h). Symptoms gradually improved. CT scan and X-ray 21 days later showed radiological improvement (Fig. 1c, d). Upon close investigation, the patient disclosed pneumonia in her pet dog 2 days before her symptoms started (Fig. 1e). Treatment of the dog with ceftriaxone plus metronidazole was apparently not effective; pneumonia was cured with subsequent erythromycin.

\section{Case \#2}

A 45-year-old man was transferred to us with fever, productive coughing, generalized muscle ache and malaise for 7 days. On the 4th day of the onset, he visited a local hospital. A chest CT scan showed consolidation in the right upper lobe (Fig. 2a). Test results included: WBC count $8.22 * 10^{9} / \mathrm{L}$, neutrophil count $7.65^{*} 10^{9} / \mathrm{L}, 93.1 \%$ neutrophils, $4.0 \%$ lymphocytes (count $0.33^{*} 10^{9} / \mathrm{L}$ ), CRP $226 \mathrm{mg} / \mathrm{L}$, ESR $42 \mathrm{~mm} / \mathrm{h}$, and PCT $1.712 \mathrm{ng} / \mathrm{ml}$. A de novo diagnosis of diabetes was also established based on repeated testing of fasting blood glucose and hemoglobin A1c. Treatment with ceftazidime ( $2 \mathrm{~g}, \mathrm{I} . \mathrm{V} ., \mathrm{q} 8 \mathrm{~h})$ and levofloxacin (500 mg, I.V., qd) was initiated for 3 days, but symptoms did not dissipate. 


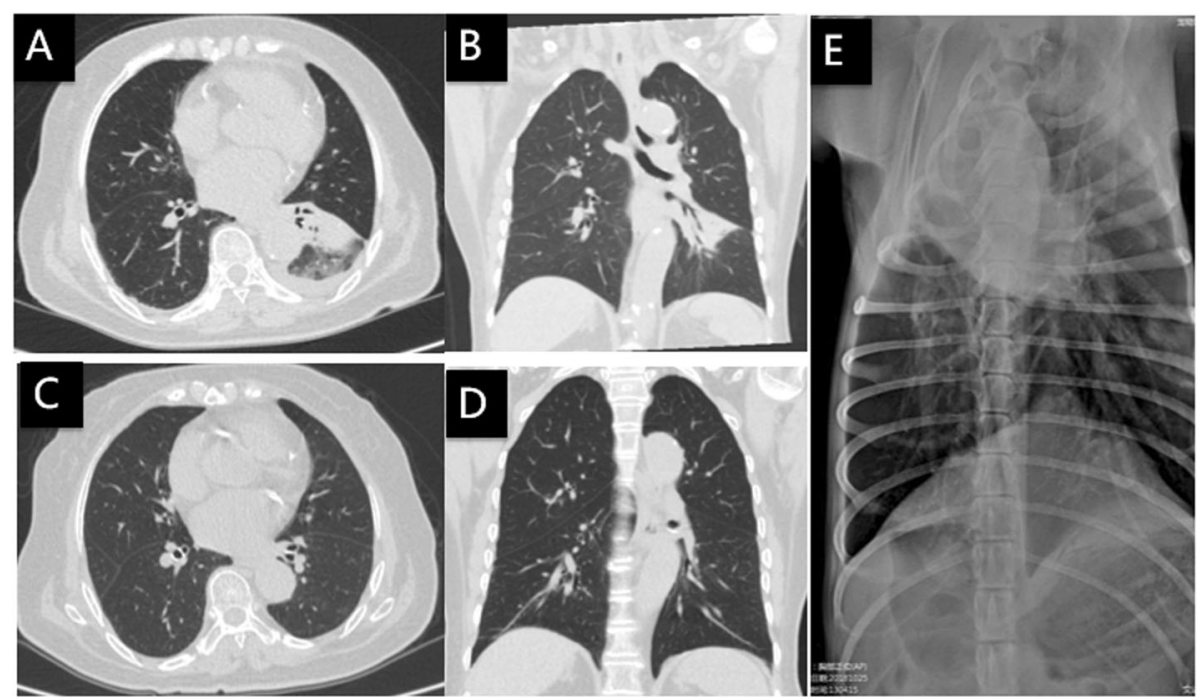

Fig. 1 Chest CT and X-ray of case 1: a, b On the day of admission, $\mathbf{c}, \mathbf{d} 21$ days after doxycycline treatment, and $\mathbf{e}$ Chest $X$ ray of patient's pet dog

Upon transferring, the body temperatures was $39.5^{\circ} \mathrm{C}$, with crackles in both lungs. The patient received ertapenan (1 g, I.V., qd) and oseltamivir (75 mg, P.O., q12h), and fever subsided in 3 days. One days later, however, he developed high fever again $\left(40^{\circ} \mathrm{C}\right)$, with signs of respiratory failure $\left(\mathrm{PaO}_{2} 40 \mathrm{mmHg}\right)$. On the 4th day of arrival to our hospital, a chest CT scan showed bilateral diffuse infiltration (Fig. 2b).

BAL was conducted at this point. BALF analysis with mNGS (BGI-Shenzhen) revealed Chlamydia psittaci as well as a few other potential pathogens (Table 1). A close inquiry yielded a 20-year history of pigeon- farming. Ertapenan and oseltamivir were discontinued. Doxycycline (100 mg, P.O., q12h) plus moxifloxacin (0.4 g, I.V., qd) was initiated. The symptoms gradually subsided. CT scans 7 days later (Fig. 2c) and 3 weeks later (Fig. 2d) showed progressive infiltrate absorption.

\section{Case \#3}

An 85-year-old previously healthy woman presented with fever, productive coughing, headache, generalized muscle ache and emesis for 2 days. A chest CT scan showed consolidation in the right upper lobe (Fig. 3a, b). Laboratory test showed $6.38^{*} 10^{9} / \mathrm{L}$ WBC count, $88.9 \%$
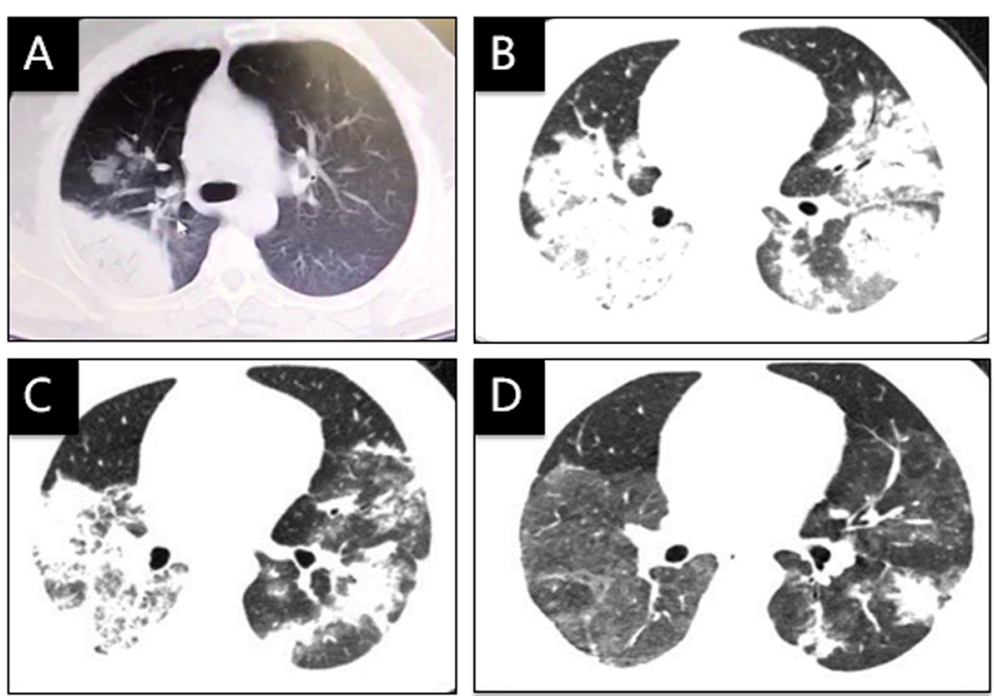

Fig. 2 Chest $C T$ of case 2: a On the 4th day of the onset, $\mathbf{b}$ On the 4th day of arrival to our hospital, $\mathbf{c} 7$ days after treatment with doxycycline plus moxifloxacin, and $\mathbf{d} 3$ weeks later after treatment with doxycycline plus moxifloxacin 

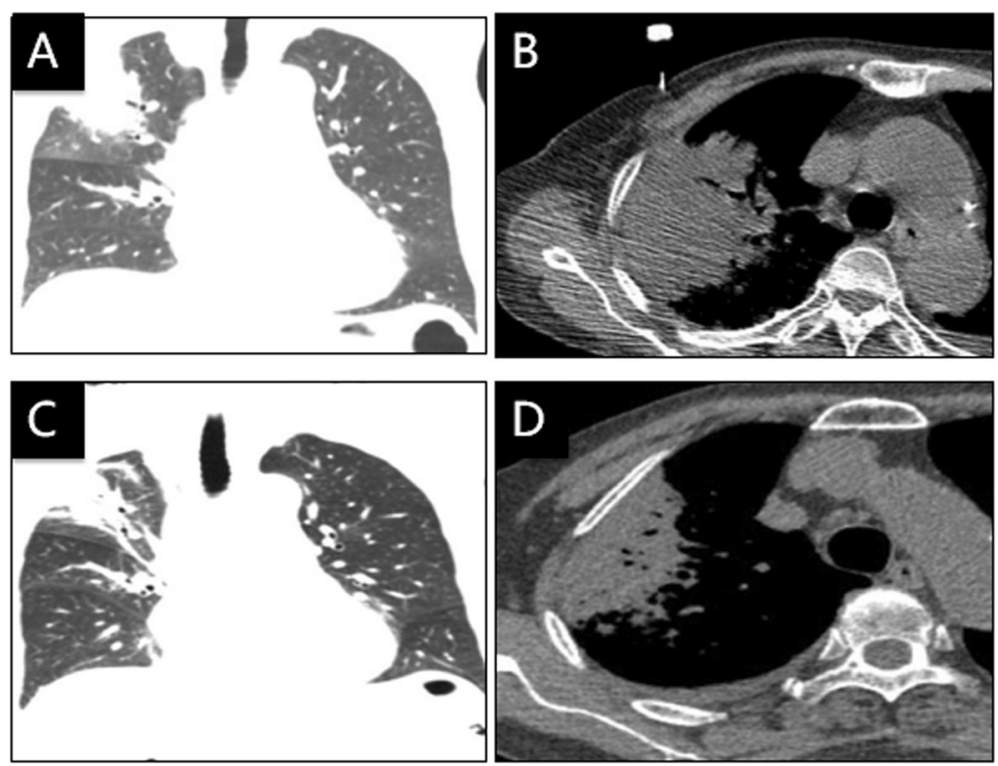

Fig. 3 Chest CT of case 3: a, b On the day of admission, $\mathbf{c}$, $\mathbf{d} 9$ days after treatment with doxycycline plus moxifloxacin

neutrophils (absolute count: $5.67^{*} 10^{9} / \mathrm{L}$ ), $8.0 \%$ lymphocytes $\left(0.51^{*} 10^{9} / \mathrm{L}\right), 184 \mathrm{mg} / \mathrm{L}$ CRP, $64 \mathrm{~mm} / \mathrm{h}$ ESR, and $1.64 \mathrm{ng} / \mathrm{ml}$ PCT.

Symptoms did not improve 3 days after ertapenem treatment $(1 \mathrm{~g}, \mathrm{I} . \mathrm{V} ., \mathrm{qd})$. Switching to biapenan $(0.6 \mathrm{~g}$, I.V., q12h) and teicoplanin (400 mg, I.V., qd) did not alleviate the symptoms. A percutaneous lung tissue biopsy was conducted; mNGS analysis (IngeniGen-Hangzhou) revealed infection with Chlamydia psittaci (Table 1). Treatment with doxycycline (100 mg, P.O., q12h) and moxifloxacin (0.4g, I.V., qd) was initiated, and the patient recovered rapidly. A CT scan 9 days later showed partial absorption of the pulmonary infiltrate (Fig. 3c, d). The patient recalled planting a vegetable plot where birds often gathered.

\section{Case \#4}

A 66-year-old woman was transferred to us with fever, rigor, dry cough and dizziness for 6 days. At the beginning of the illness, she received levofloxacin and cefotaxime in a local hospital but symptoms persisted. A chest CT scan upon transferring showed consolidation in the right upper lobe (Fig. 4a, b). Laboratory test showed $5.47^{*} 10^{9} / \mathrm{L}$ WBC count, $69.8 \%$ neutrophils $\left(3.82^{*} 10^{9} / \mathrm{L}\right)$, $19.4 \%$ lymphocytes $\left(1.06 * 10^{9} / \mathrm{L}\right), 124 \mathrm{mg} / \mathrm{L}$ CPR, $17 \mathrm{~mm} /$ h ESR, and $0.13 \mathrm{ng} / \mathrm{ml}$ PCT. Treatment with moxifloxacin $(0.4 \mathrm{~g}, \mathrm{I} . \mathrm{V} ., \mathrm{qd})$ was initiated, and body temperature returned to normal within 2 days. A percutaneous lung biopsy was conducted; the sample testing with mNGS (IngeniGen-Hangzhou) detected Chlamydia psittaci (Table 1). Later, we learned that she had close contact with a large poultry farm on a daily basis. Moxifloxacin treatment lasted for 10 days. CT scan 8 days after moxifloxacin treatment initiation (Fig. 4c) and 16 days after discontinuation showed gradual infiltrate absorption (Fig. 4d).

\section{Case \#5}

A 61-year-old woman presented with fever, rigor, weakness, productive coughing and dizziness for 3 days. A chest CT scan showed patchy infiltration and consolidation of both lungs (Fig. 5a, b, c). Laboratory test showed $6.88^{*} 10^{9} / \mathrm{L}$ WBC count, $68.4 \%$ neutrophils $\left(4.70 * 10^{9} / \mathrm{L}\right)$, $22.7 \%$ lymphocytes $\left(1.56 * 10^{9} / \mathrm{L}\right), 96.7 \mathrm{mg} / \mathrm{L}$ CRP, $37 \mathrm{~mm} /$ $\mathrm{h}$ ESR, and normal PCT. She disclosed close contact with a pet parrot. She was treated with moxifloxacin and her body temperature returned to normal on the next day. Analysis of lung biopsy tissue with mNGS (IngeniGen-Hangzhou) reported Chlamydia psittaci (Table 1). A CT scan 8 days later showed partial absorption of the pulmonary infiltrate (Fig. 5d, e, f).

\section{Discussion and conclusions}

Chlamydia psittaci can be classified into 10 genotypes, with varying preference for host species [5]. Genotype A and $\mathrm{E}$ could infect humans. After entry via contaminated aerosols, Chlamydia psittaci spreads to the reticuloendothelial system. The lungs are the most common sites of Chlamydia psittaci infection. Chlamydia psittaci pneumonia is estimated to account for approximately $1 \%$ of community-acquired pneumonia cases [3, 6]. Symptoms mimics that of influenza, and typically include fever, fatigue, headache, myalgia, and coughing $[7,8]$. 

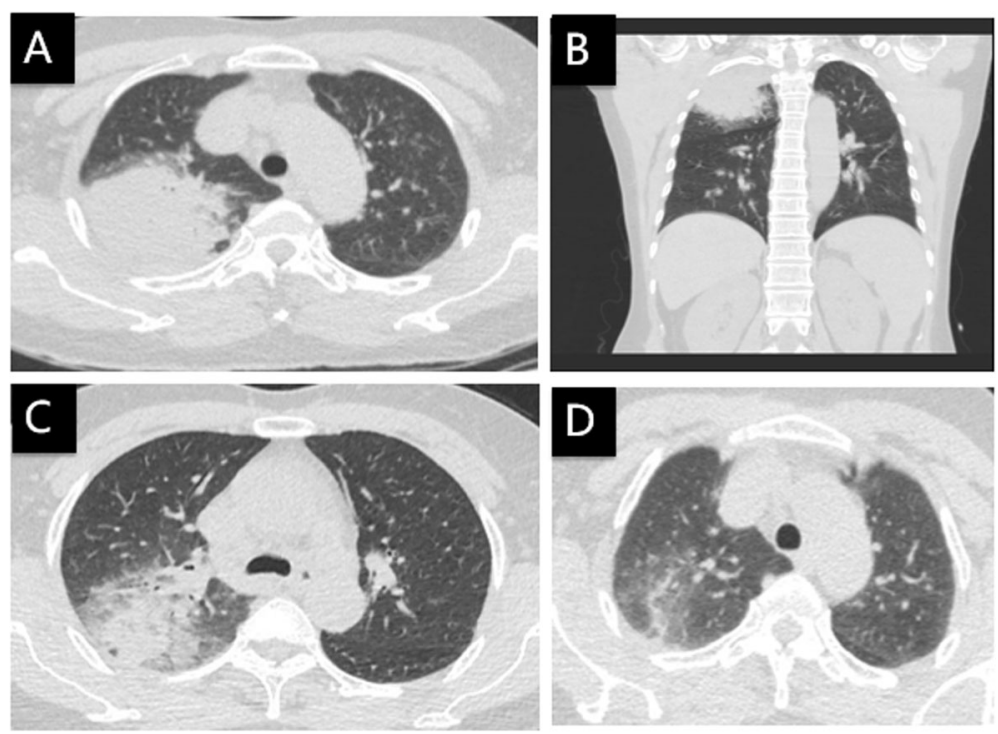

Fig. 4 Chest $C T$ of case 4: a, b On the day of admission, c Eight days after treatment with moxifloxacin, and $\mathbf{d}$ Sixteen days after discontinuation

In 4 out of the 5 cases in this report, patients had contacts with birds (parrot and pigeon) or poultry, suggesting the need to investigate such exposure upon suspected cases. Two out of the 5 patients had diabetes; and the other 3 were otherwise healthy, suggesting that Chlamydia psittaci could infect human subjects regardless of underlying diseases.

Chlamydia psittaci infection tends to be overlooked due to relatively low awareness by physicians. Laboratory testing for Chlamydia psittaci includes culture, serological assay, and PCR. Culture is time consuming, and most formidably, requires P3 facility [6]. Serological tests are only appropriate for retrospective diagnosis because sera from the both acute and convalescent phase of the illness are required [9]. PCR-based testing is the most specific and fastest method but only sensitive in the acute phases of the infection [2]. The current case series indicated that mNGS could be used to diagnose Chlamydia psittaci infection. If using a set of universally accepted standards, mNGS could even provide semiquantitative information (based on sequence reads) about the load of Chlamydia psittaci, such information could be critically important in determining whether a specific microbe is the causative pathogen(s) in polymicrobial samples. The limitations of mNGS analysis, for infection with a Chlamydia psittaci or any other agent, include host background sequences. In future studies,

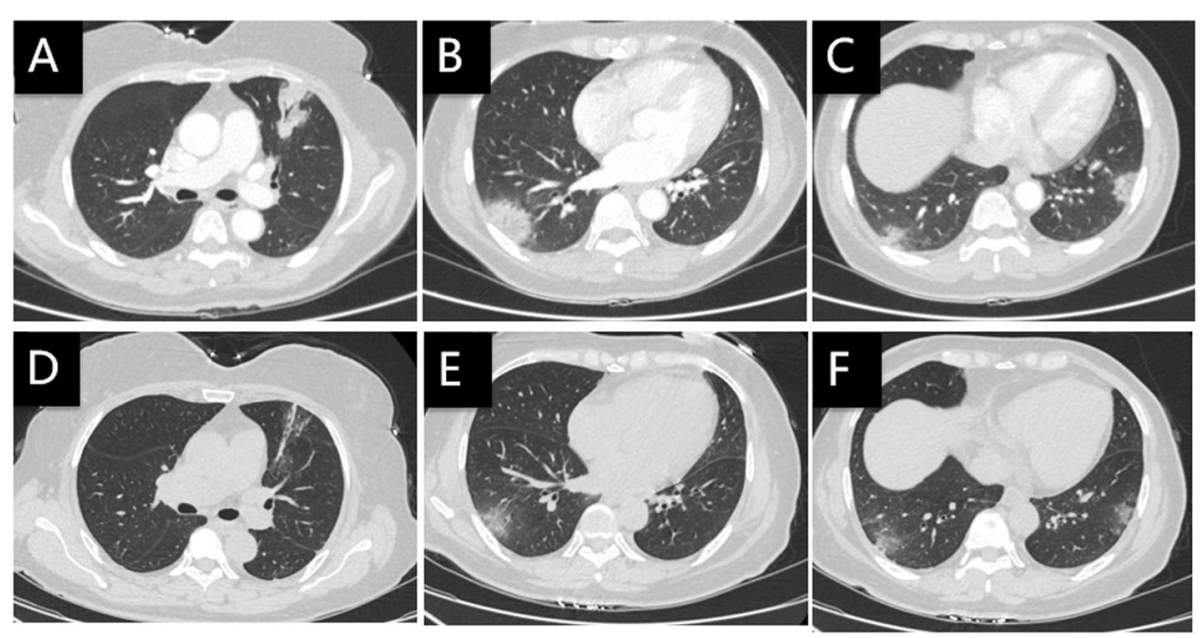

Fig. 5 Chest $C T$ of case 5: a, b, c On the day of admission, d, e, f Eight days after treatment with moxifloxacin 
targeted sequencing and host depletion methods could be used to minimize the human host background, workflow quality control procedures could be optimized to reduce false positives. It is also likely that Chlamydia psittaci is merely present in the sample and not the culprit of infection. The fact that many other pathogens, including Candida albicans, have been identified in the 5 cases illustrate the complexity and a need to integrate the mNGS results into the overall clinical scenario. Lack of verification with serologic tests and/or culture is a significant limitation in the current study. These findings therefore must be interpreted with caution.

In the current series, mNGS was conducted only after initial empirical antibiotic treatment failed to control the infection in 4 out of the 5 cases. Considering the feasibility and cost of mNGS, we believed the timing of mNGS is appropriate, and recommend mNGS testing only if patients do not respond to treatments against other more common causes.

The specific reads for Chlamydia psittaci ranged from 2 to 225 in the 5 cases. Comparison across cases is not possible since the assay was conducted by several different companies. In case $\# 1$ and $\# 5$, the detected Chlamydia psittaci reads were 6 and 2, respectively. We speculate that the relatively low specific reads of Chlamydia psittaci in Case \#1 may reflect the therapeutic effects of moxifloxacin, albeit not adequate. In Case $\# 5$, the low specific reads of Chlamydia psittaci may reflect the loss of biological activity of pathogens and degradation of nucleic acid during the process of sample collection and transportation or the treatments that the patient received prior to sample collection.

Recommended treatment for Chlamydia psittaci pneumonia included tetracycline, macrolide and quinolones [10]. Treatment must continue for at least 1014 days to prevent relapse. In case \#1, moxifloxacin was used as an initial treatment for 3 days, but no significant improvement was obtained. In our opinion, the lack of response to moxifloxacin in this case could be due to several reasons, including: 1) possible superinfection by other agents that could be readily controlled by doxycycline; 2) relative insensitivity of the Chlamydia psittaci isolate in this specific case to moxifloxacin. Indeed, recommended first-line treatment of Chlamydia psittaci pneumonia is doxycycline and not quinolones [11].

In conclusion, the current series suggested that mNGS could be used in diagnosing Chlamydia psittaci infection. This preliminary finding should be examined with diagnostic trial in the future.

\section{Abbreviations}

BAL: Bronchoalveolar lavage; BALF: Bronchoalveolar lavage fluid; CRP: C reactive protein; CT: Computed tomography; ESR: Erythrocyte sedimentation rate; LN: Lymphocyte; mNGS: Metagenomic next-generation sequencing; NE: Neutrophil; PCR: Polymerase chain reaction; PCT: Procalcitonin; WBC: White blood cell

\section{Acknowledgements}

The authors thank the five patients and their families for agreeing to use their data for research purposes, and specifically, for publication of this report.

\section{Authors' contributions}

$L G$ and $W L$ contributed equally to this work. $L G, W L, M R$, JL and GQY participated in manuscript drafting. JY, ZAZ, YBL and JC collected and analyzed clinical data. WL, GXL, WW participated in data interpretation and manuscript revision. All authors read and approved the final manuscript.

\section{Funding}

This work was supported by Clinical Key Specialty Construction Project in Fujian Province (No. 2015-593).

Availability of data and materials

All the data supporting our findings is contained within the manuscript.

Ethics approval and consent to participate

Not applicable.

\section{Consent for publication}

All 5 patients provided written consent to use their data for research purposes, and specifically, for publication of this manuscript.

\section{Competing interests}

The authors declare that they have no competing interests.

\section{Author details}

${ }^{1}$ Graduate College of Fujian Medical University, Minhou, Fuzhou 350108, China. ${ }^{2}$ Department of Respiratory and Critical Care Medicine, Dongfang Hospital of Xiamen University, Fuzhou General Hospital of Fujian Medical University, The 900th Hospital of the Joint Logistic Support Force, PLA, Gulou, Fuzhou 350025, China. ${ }^{3}$ Pharmacy Department, The 985th Hospital of the Joint Logistic Support Force, PLA, Yingze, Taiyuan 030001, China. ${ }^{4}$ Department of Nephrology, Dongfang Hospital of Xiamen University, Fuzhou General Hospital of Fujian Medical University, The 900th Hospital of the Joint Logistic Support Force, PLA, Gulou, Fuzhou 350025, China.

Received: 6 November 2019 Accepted: 24 February 2020

Published online: 17 March 2020

\section{References}

1. de Gier B, Hogerwerf L, Dijkstra F, van der Hoek W. Disease burden of psittacosis in the Netherlands. Epidemiol Infect. 2018;146:303-5.

2. Nieuwenhuizen AA, Dijkstra F, Notermans DW, van der Hoek W. Laboratory methods for case finding in human psittacosis outbreaks: a systematic review. BMC Infect Dis. 2018;18(442):1-16.

3. Hogerwerf L, DE Gier B, Baan B, Van Der Hoek W. Chlamydia psittaci (psittacosis) as a cause of community-acquired pneumonia: a systematic review and meta-analysis. Epidemiol Infect. 2017;145:3096-105.

4. Gu W, Miller S, Chiu CY. Clinical metagenomic next-generation sequencing for pathogen detection. Annu Rev Pathol. 2019;14:319-38.

5. Radomski N, Einenkel R, Muller A, Knittler MR. Chlamydia-host cell interaction not only from a bird's eye view: some lessons from chlamydia psittaci. FEBS Lett. 2016:590:3920-40.

6. Balsamo G, Maxted AM, Midla JW, Murphy JM, Wohrle R, Edling TM, et al. Compendium of measures to control chlamydia psittaci infection among humans (psittacosis) and pet birds (avian Chlamydiosis), 2017. J Avian Med Surg. 2017;31:262-82.

7. Branley JM, Weston KM, England J, Dwyer DE, Sorrell TC. Clinical features of endemic community-acquired psittacosis. New Microbes New Infect. 2014;2: 7-12.

8. Homma T, Yamaguchi T, Komatsu N, Hashimoto S, Doki Y, Senda K, et al. A case of acute psittacosis with severe abdominal pain. J Med Microbiol. 2011; 60:547-9. 
9. Tuuminen T, Palomaki P, Paavonen J. The use of serologic tests for the diagnosis of chlamydial infections. J Microbiol Methods. 2000;42(3):265-79.

10. Cilloniz C, Torres A, Niederman M, van der Eerden M, Chalmers J, Welte T, et al. Community-acquired pneumonia related to intracellular pathogens. Intensive Care Med. 2016;42(9):1374-86.

11. Mandell LA, Wunderink RG, Anzueto A, Bartlett JG, Campbell GD, Dean NC, et al. Infectious Diseases Society of America/American Thoracic Society consensus guidelines on the management of community-acquired pneumonia in adults. Clin Infect Dis. 2007;44(Suppl 2):S27-72.

\section{Publisher's Note}

Springer Nature remains neutral with regard to jurisdictional claims in published maps and institutional affiliations.

Ready to submit your research? Choose BMC and benefit from:

- fast, convenient online submission

- thorough peer review by experienced researchers in your field

- rapid publication on acceptance

- support for research data, including large and complex data types

- gold Open Access which fosters wider collaboration and increased citations

- maximum visibility for your research: over $100 \mathrm{M}$ website views per year

At $\mathrm{BMC}$, research is always in progress.

Learn more biomedcentral.com/submissions 